\title{
Iron stores in Chinese eligible male plateletpheresis donors
}

\author{
Lei Shao ${ }^{1}{ }^{\text {, Jinhua } \mathrm{Wang}^{2} \triangle}$, Shaowen Zhu ${ }^{1}$, Hong $\operatorname{Lin}^{2 *}$ \\ ${ }^{I}$ Transfusion Research Laboratory, Jiangsu Province Blood Center, Nanjing, Jiangsu 210042, China; \\ ${ }^{2}$ Clinical Laboratory, Jiangsu Province Blood Center, Nanjing, Jiangsu 210042, China
}

\begin{abstract}
Plateletpheresis donors may become iron deficient, particularly if donating at the maximum suggested interval of every 2 weeks. This study aimed to evaluate iron stores in male Chinese plateletpheresis donors. Serum samples were collected from 445 male plateletpheresis donors and serum ferritin (SF) levels were measured. There were 16 repeat donors $(3.6 \%)$ with iron deficiency $(\mathrm{SF}<10 \mathrm{ng} / \mathrm{mL})$, but none was found in first time donors. About $63(14.2 \%)$ had depleted iron stores $(\mathrm{SF}<30 \mathrm{ng} / \mathrm{mL})$, including two first time donors $(0.4 \%)$. Repeat donors had lower mean SF levels than the first donors. There was a positive correlation between iron deficiency/depletion prevalence, lower hemoglobin level and number of platelet donations. Donation interval, age and ABO blood groups were not associated with iron status. Iron status needs to be monitored in repeat platepheresis donors and donors with $\mathrm{Hb}<130 \mathrm{~g} / \mathrm{L}$, especially when the number of donations are between 10 and 30. For these individuals, SF measurement and iron supplementation are recommended.
\end{abstract}

Keywords: serum ferritin, depleted iron stores, iron deficiency, plateletpheresis donors

\section{INTRODUCTION}

One major concern for whole blood donors is a potential progressive decline in iron reserves due to red blood cell loss ${ }^{[1]}$. To explore this, iron status and the prevalence of iron deficiency in whole blood donors have been investigated in many countries and regions ${ }^{[2-6]}$. A plateletpheresis donor however, may lose $80-100 \mathrm{~mL}$ of whole blood during every platelet donation, which is thought not to affect iron stores ${ }^{[7]}$, allowing for more frequent donations than whole blood donor. Before 2012 in China, the minimum platelet donation interval was set at 4 weeks, however since 2012 this limit has been revised to a minimum interval of 2 weeks, but no more than 24 times a year. If a plateletpheresis donor donates at the maximum recommended frequency, this will result in an annual blood loss of up to $2400 \mathrm{~mL}$. Therefore, since the maximum whole blood donation is $300 \mathrm{~mL}$ or $400 \mathrm{~mL}$ and the minimal interval is 6 months, this equates to $6 \sim 8$ whole blood donations in one year. This suggests that iron status needs to be paid attention to in plateletpheresis donors, at least as much as for whole blood donors.

In order to qualify as a plateletapheresis donor, it is necessary to pass Chinese health administration defined minimum hemoglobin $(\mathrm{Hb})$, hematocrit and platelet count number. However, there is no requirement for evaluating iron levels. Some studies have reported iron status in plateletpheresis donors in other countries such as Australia, UK, Denmark and India, and repeat plateletapheresis donors have shown de-

\footnotetext{
*Correspondence to: Hong Lin, Transfusion Research Laboratory, Jiangsu Province Blood Center. 179 Longpan Road, Nanjing, Jiangsu 210042, China. TEL: +86-25-85411563; E-mail: linhong712003@sina.com.

Conflict of interests: The authors have declared no conflict of interests.

${ }^{\triangle}$ The authors contributed equally to this article.
} 
creased serum ferritin (SF) levels in line with donations over time ${ }^{[6-11]}$. Few studies have investigated iron status among plateletpheresis donors in Chi$\mathrm{na}^{[12,13]}$. Although regular plateletpheresis donors had lower SF levels, their averages remain normal, i.e. not low enough to change platelet function ${ }^{[14]}$. However, the prevalence of iron deficiency and depletion in donors still remains unclear. This study aimed to evaluate iron levels and investigate the effects of regular plateletpheresis on donors' iron stores, and in addition the association between iron status and $\mathrm{Hb}$ level, the number of donations, donation frequency, age and blood groups of plateletpheresis donors.

\section{MATERIALS AND METHODS}

\section{Blood samples}

According to Whole Blood and Component Donor Selection Requirements(GB 18467-2011) for blood donations in China, all donors were asked to fill in a risk factor questionnaire to exclude those at risk of exposure to transfusion-transmissible infections(TTIs). In our blood centre, all donors were pre-screened for hemoglobin $(\mathrm{Hb})$ by copper sulfate solution and for HBsAg and Treponema pallidum antibody with a rapid co-assay(colloidal gold strip method, Xinchuang Xiamen, China) and deferred if positive. ALT testing (Reflotron system, Roche, Shanghai, China) was also performed prior to donation and donors were deferred if their ALT was abnormal ( $>40 \mathrm{U} / \mathrm{L})$. Blood samples were collected for routine screening TTIs markers. For plateletpheresis donors, additional full blood counts were performed, including $\mathrm{Hb}$, Hematocrit (Hct), RBC count, platelet count and leucocyte count. All above results and demographic information concerning the donors were recorded on computer. Between March 2nd and 15th 2018, blood samples were collected after TTIs marker screening and were stored at $-80^{\circ} \mathrm{C}$. This study was approved by Ethics Committee in our blood center (JSBC 2017-03) which permitted the use of these samples and donor information from database.

\section{Equipment and assays}

$\mathrm{Hb}$ and blood cell variables were determined using a hematology analyzer (Sysemex XT-1800i, Japan) before donation, according to the admission threshold of blood donation for males $(\mathrm{Hb} \geqslant 120 \mathrm{~g} / \mathrm{L})$. Additional requirements for platelet donors were Hct $\geqslant 0.36$, platelet number $\geqslant 130 \quad 109 / \mathrm{L}$ and $\leqslant 450 \times 10^{9} / \mathrm{L}$. SF was tested using chemiluminescense immunoquantification kits(Wantai, Beijing, China) by automatic biochemical instrument (AU400, Olympus, Japan). The reference ranges for SF were $30-300 \mathrm{ng} / \mathrm{mL}$ for males. $\mathrm{SF}<10 \mathrm{ng} / \mathrm{mL}$ was suggested as iron deficient and $10-30 \mathrm{ng} / \mathrm{mL}$ as depleted iron stores, according to the manufacturer's instructions and referring to a previous study ${ }^{[5]}$.

\section{Statistical analysis}

Descriptive statistics were performed for the donors' characteristics and laboratory variables obtained. The Chi-square test was performed to examine any significance in the prevalence of iron deficiency and iron stores depleted donors among the groups for male donors. Mann-Whitney and Kruskal-Wallis tests were used to determine statistical difference in subgroup analysis. Statistical analyses were conducted with computer software (Prism, Version 5.04, GraphPad, SanDiego, CA; SPSS, version 19.0, Chicago, USA). A two-sided $P$ value of less than 0.05 was denoted significant

\section{RESULTS}

A total of 509 samples were screened for TTIs markers. Nine samples who were once tested positive for infectious markers were excluded. SF testing was carried out on five hundred samples consisting of 445 male donors and 55 female donors. For this study we reported the results of iron stores in the male donors only, including 44 first time donors and 401 repeat donors (defined as having donated more than once).

\section{Iron stores and number of donation}

Iron deficiency was detected in all 16 repeat donors, but none in the first time donors. The iron depletion rate was $14.2 \%$ (63), which included 2 first time donors. Twenty two(4.9\%) donors had a high iron stores with $\mathrm{SF}>300 \mathrm{ng} / \mathrm{mL}$.

According to the number of donations, donors were divided into six groups. SF distribution in different groups was illustrated in Fig. 1. The median of SF level was the highest in Group 1(first time donors) and decreased with increasing donation times. Group 2 (1-10 times) had lower SF levels than Group 1, but no significant difference was found $(P>0.05)$. When the last four groups' median SF level were compared, we found the decrease was steady $(P>0.05)$. When the number of donation was more than 10 , the median $\mathrm{SF}$ had a statistically significant decline $(P<0.0001)$.

The prevalence of iron status in donors with different numbers of donation was summarized in Table 1. Repeated donors were placed in four groups, from 11-172 times. Those who had donated 11-30 times had the lowest prevalence of iron deficiency. With increasing donation times, the percentage of iron deficiency rose accordingly, however no significance 


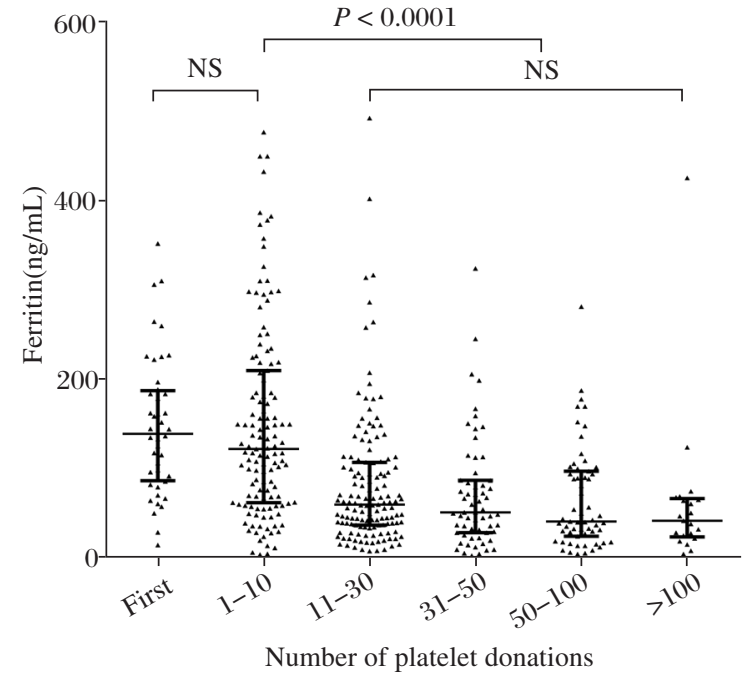

Fig. 1 Distribution of iron concentration among six groups of donors. Error bars represented the median with interquartile range. $\mathrm{NS}=$ no significant $(P>0.05)$. was found $(P=0.09)$. The prevalence of depleted iron stores also increased with increasing number of donations, showing a significant difference $(P=0.005)$.

\section{Iron stores and donation interval}

A total of 152 platepheresis donors had at least one whole blood donation experience in their donation history. There were 6 with iron deficiency and 20 with depleted iron stores. When the donors started donating platelets, most of them stopped donating whole blood. The iron status results showed no difference between whole blood donors and platelet only donors. There were 33 donors who donated one whole blood in the past year. No one had iron deficiency and only $2(6.1 \%)$ had depleted iron stores.

The prevalence of iron deficiency and depletion among different donation intervals in repeat donors was compared in the past year (Table 2). Quite unex-

Table 1 Prevalence of iron stores and different numbers of donation

\begin{tabular}{lcccccc}
\hline \multirow{2}{*}{ Donation times } & \multirow{2}{*}{ Donors $(n)$} & \multirow{2}{*}{ Mean SF $(\mathrm{g} / \mathrm{L})$} & \multicolumn{4}{c}{$\mathrm{SF}[n(\%)]$} \\
\cline { 4 - 7 } & & & $<10 \mathrm{ng} / \mathrm{mL}$ & $10-30 \mathrm{ng} / \mathrm{mL}$ & $30-300 \mathrm{ng} / \mathrm{mL}$ & $>300 \mathrm{ng} / \mathrm{mL}$ \\
\hline First & 44 & 147.1 & 0 & $2(4.6)$ & $39(88.6)$ & $3(6.8)$ \\
$1-10$ & 126 & 149.4 & $2(1.4)$ & $6(4.8)$ & $113(89.6)$ & $4(3.2)$ \\
$11-30$ & 134 & 84.3 & $4(6.6)$ & $12(19.7)$ & $44(72.1)$ & $13(9.7)$ \\
$31-50$ & 61 & 71.5 & $5(8.5)$ & $12(20.3)$ & $42(71.2)$ & $0(0)$ \\
$51-100$ & 59 & 66.2 & $2(9.5)$ & $6(28.6)$ & $12(57.1)$ & $1(4.8)$ \\
$101-172$ & 21 & 63.1 & $16(3.6)$ & $63(14.2)$ & $344(77.3)$ & $22(4.9)$ \\
Total & 445 & 103.7 & & &
\end{tabular}

pectedly, the 6-7 week interval had the highest iron deficiency percentage. No iron deficiency was found when the donation interval was 8 weeks or more. There was no significance between different intervals and iron deficiency $(P=0.56)$, but depleted iron stores was found at every interval and correlated with interval $(P=0.005)$.

Table 2 Donation interval and iron status

\begin{tabular}{lccc}
\hline $\begin{array}{c}\text { Donation interval } \\
\text { in the past year }\end{array}$ & Donors $(n)$ & $\begin{array}{c}\text { Iron deficiency } \\
{[n(\%)]}\end{array}$ & $\begin{array}{c}\text { Depleted iron stores } \\
(n[\%])\end{array}$ \\
\hline 2 weeks & 134 & $7(5.2)$ & $24(17.9)$ \\
3 weeks & 111 & $5(4.5)$ & $20(18.0)$ \\
4-5 weeks & 64 & $1(1.6)$ & $10(15.6)$ \\
6-7 weeks & 40 & $3(7.5)$ & $2(5.0)$ \\
8-10 weeks & 20 & 0 & $3(15.0)$ \\
$13-17$ weeks & 14 & 0 & $1(7.1)$ \\
Above 20 weeks & 18 & 0 & $1(5.6)$ \\
Total & 401 & $16(4.0)$ & $61(15.2)$ \\
\hline
\end{tabular}

\section{on stores and $\mathrm{Hb}$ levels}

The number of iron deficiency or depletion of donors in different $\mathrm{Hb}$ groups were shown in Fig. 2. Among donors with $\mathrm{Hb}$ scores of 120-129, 130-139, $140-149$ and $\geqslant 150 \mathrm{~g} / \mathrm{L}$, the prevalence of iron deficiency was $41.2 \%, 20.0 \%, 0.8 \%$ and 0 , respectively. The prevalence of depleted iron stores was $41.2 \%$,
$17.5 \%, 17.8 \%$ and $10.4 \%$, respectively. Significant difference was found between $\mathrm{Hb}$ level and iron deficiency $(P<0.01)$ and depleted iron stores $(P<0.05)$.

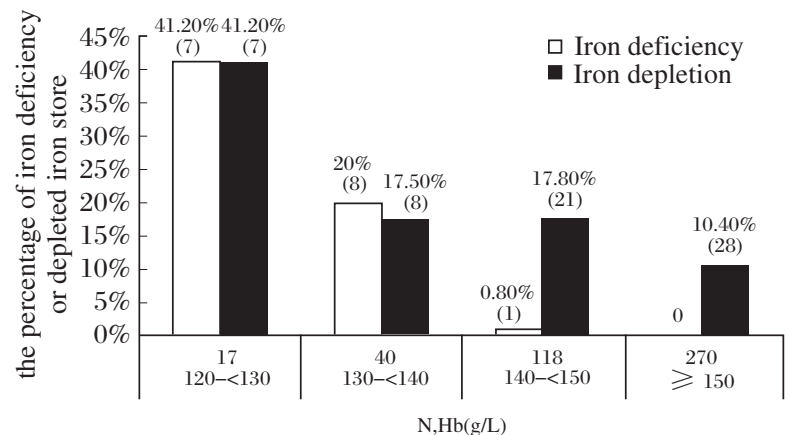

Fig. 2 The percentage of iron deficiency or depletion donors stratified by their hemoglobin

\section{Iron stores and age}

Donors with different ages were divided into three groups: 19-30, 31-45 and 46-60 years old. The group of 31-45 years old donors had the highest prevalence of depleted iron stores and the lowest prevalence of iron deficiency. Their mean SF concentration was the lowest. Age was associated with the prevalence of depleted iron stores $(P=0.026)$ but not with the prevalence of iron deficiency $(P=0.818$, Table 3$)$. 
Table 3 Correlation of age and iron stores

\begin{tabular}{cccccccc}
\hline \multirow{2}{*}{ Age range } & \multirow{2}{*}{ Mean age } & \multirow{2}{*}{$N$} & \multirow{2}{*}{ Mean SF $(\mathrm{g} / \mathrm{L})$} & \multicolumn{4}{c}{$\mathrm{SF}[n(\%)]$} \\
\cline { 5 - 8 } & & & & & & \multicolumn{3}{c}{$30 \mathrm{ng} / \mathrm{mL}$} & $10-30 \mathrm{ng} / \mathrm{mL}$ & $30-300 \mathrm{ng} / \mathrm{mL}$ & $300 \mathrm{ng} / \mathrm{mL}$ \\
\hline $19-30$ & 26 & 192 & 104.7 & $8(4.2)$ & $22(11.5)$ & $155(80.7)$ & $7(3.6)$ \\
$31-45$ & 35 & 140 & 98.8 & $4(2.9)$ & $29(20.7)$ & $98(70.0)$ & $9(6.4)$ \\
$46-60$ & 49 & 113 & 108.3 & $4(3.5)$ & $12(10.7)$ & $91(80.5)$ & $6(5.3)$ \\
Total & 34 & 445 & 103.7 & $16(3.6)$ & $63(14.2)$ & $344(77.3)$ & $22(4.9)$ \\
\hline
\end{tabular}

\section{Iron status and $\mathrm{ABO}$ blood groups}

Compared to non-O blood group (A, $\mathrm{AB}$ and $\mathrm{B}$ blood groups) donors, $\mathrm{O}$ blood donors had a higher prevalence of iron deficiency $(5.5 \%, 7 / 129$ vs. $2.8 \%$, 9/316). In depleted iron stores donors, 17 (13.2\%) were O blood and 46 (14.6\%) were non-O. No significant difference was found between iron status and ABO blood groups(iron deficiency: $P=0.185$; depleted iron stores: $P=0.742$ ).

\section{Multivariable analysis of the factors influ- encing iron stores}

Here we set $\mathrm{SF}<30 \mathrm{ng} / \mathrm{mL}$ as reduced iron stores, univariate analysis and multivariate analysis were run to analyze the factors influencing iron stores (Table 4). From the univariate analysis, $\mathrm{Hb}$ and the number of donations were found to be significantly associated with reduced iron stores. Age, donation interval and ABO blood types all had no correlation with reduced iron stores. Multivariate analysis demonstrated that $\mathrm{Hb}$ and the number of donations were the independent factors for reduced iron stores.

\section{DISCUSSION}

This was the first study to determine iron status in local plateletapheresis donors in China. When iron sta-

Table 4 Univariate and multivariate hazard analysis of factors influencing reduced iron stores

\begin{tabular}{|c|c|c|c|c|}
\hline \multirow{2}{*}{ Factors } & \multicolumn{2}{|c|}{ Univariate-analysis } & \multicolumn{2}{|c|}{ Multivariate analysis } \\
\hline & $P$-value & $\mathrm{HR}(95 \% \mathrm{CI})$ & $P$-value & $\mathrm{HR}(95 \% \mathrm{CI})$ \\
\hline Age & 0.566 & $1.006(0.985,1.028)$ & 0.274 & $0.986(0.961,1.011)$ \\
\hline $\mathrm{Hb}$ & 0.000 & $0.916(0.898,0.934)$ & 0.000 & $0.027(0.000,0.072)$ \\
\hline Number of donation & 0.000 & $1.542(1.317,1.806)$ & 0.001 & $1.34(1.155,1.682)$ \\
\hline Donation interval & 0.148 & $0.207(0.128,0.335)$ & 0.072 & $0.0000(000,0.072)$ \\
\hline ABO blood type & 0.063 & $1.552(0.976,2.470)$ & 0.934 & $0.057(0.041,0.665)$ \\
\hline
\end{tabular}

HR: Hazard ratios ;95\% CI:95\% confidence intervals.

tus was evaluated by SF, 3.6\% (16/445) of all male donors were classified as iron deficiency $(\mathrm{SF}<\mathrm{l0} \mathrm{ng} / \mathrm{mL})$, while no first time donors had iron deficiency. A study reported that anemia affected $9.7 \%$ of all people over 6 years old in Chinese general population ${ }^{[15]}$, with $1.6 \%$ of all males having a depleted iron stores ${ }^{[16]}$. Plateletpheresis donors' iron store has been reported in some countries. In the UK, one report showed that $32.6 \%$ of donors(donated for less than 3 years) and $40 \%$ (donated for more than 3 years) had low iron stores below the normal range of $30-400 \mathrm{ng} / \mathrm{mL}$, as indicated by $\mathrm{SF}^{[8]}$. In our study, $17.8 \%(79 / 445)$ had low iron stores $(\mathrm{SF}<30 \mathrm{ng} / \mathrm{mL})$. In Ireland, $\mathrm{SF}<20 \mathrm{ng} / \mathrm{mL}$ was found in $9 \%(6 / 64)$ of plateletpheresis donors ${ }^{[1]}$. A report in Australia showed $1.3 \%$ of new male donors and $2.2 \%$ of regular male donors had iron deficiency $(\mathrm{SF}<15 \mathrm{ng} / \mathrm{mL})^{[6]}$. Although the SF threshold was different, our results indicated that low level SF Chinese plateletpheresis donors deserved close attention.

The correlation between the prevalence of depleted iron stores and the number of donations is controversial. Page et al. concluded that there was no correlation between the number of donations over a lifetime and iron status ${ }^{[8]}$. Salvin et al. thought that apheresis donors did not appear to be at increased risk of iron deficiency compared with new donors ${ }^{[6]}$. A pilot study, which used more iron and erythropoiesis related parameters, confirmed that donation frequency was correlated inversely with SF in donors ${ }^{[10]}$. In our study, the rate of $\mathrm{SF}$ below $<30 \mathrm{ng} / \mathrm{mL}$ increased with increasing donations, albeit the prevalence of iron deficiency increased steadily and was not found to have significant difference. Multivariate analysis also verified that the number of donations correlated with iron stores.

In a study performed in 2010 at our blood center, 4 out of 97 blood donors $(4.1 \%)$, including 1 out of 72 males $(1.4 \%)$, were found to have iron deficiency ${ }^{[13]}$. Before 2011, Whole Blood and Component Donor Selection Requirements (GB18467-2001) in China, stipulated a minimum platelet donation interval of 4 weeks. Later however, this requirement was adjusted to 2 weeks (GB18467-2011) in 2011. This study found the prevalence of iron deficiency to be increased to $3.6 \%$. This demonstrated that a shortened donation interval slightly increased the rate of iron deficiency, 
as shown in Table 2. With increasing knowledge of iron deficiency relating to blood donations, many countries have begun to monitor iron stores in repeated blood donors and adjusted donation intervals ${ }^{[9-11]}$. In this study, no correlation between prevalence of reduced iron stores and interval was found. Multivariate analysis also supported this conclusion, however it should be noted that the prevalence of depleted iron stores was high. Surveys on more samples are needed to provide strong evidence to understand the effects of different plateletpheresis intervals in China.

It was considered that measures of $\mathrm{Hb}$ or Hct measurements did not accurately reflect donor's iron stores, and $\mathrm{Hb}$ may be a poor predictor of iron deficiency ${ }^{[1]}$. In most Western countries, male donors are eligible to make an apheresis donation if their minimum $\mathrm{Hb}$ is $125 \mathrm{~g} / \mathrm{L}$ or higher. In China, a slightly lower minimum $\mathrm{Hb}$ level of $120 \mathrm{~g} / \mathrm{L}$ for males is required for donation. While plateletapheresis donors are able to maintain their $\mathrm{Hb}$, Hct and red blood cell count prior to donation, some were unaware of their depleting iron stores. In this investigation, low $\mathrm{Hb}$ level donors $(<130 \mathrm{~g} / \mathrm{L})$ were taken to have more iron deficiency prevalence. If the $\mathrm{Hb}$ level was set to $130 \mathrm{~g} / \mathrm{L}$ for male donors according to WHO standard ${ }^{[17]}, 7$ donors should be deferred to donate out of 16 iron deficiency donors. The iron deficiency prevalence would be changed tol.8\%. As thus, elevating minimum $\mathrm{Hb}$ in Chinese blood donors may decrease the rate of iron deficiency. In a random clinical trial of American whole blood donors, iron supplementation reduced the high rate of low-hemoglobin donor deferrals based on capillary hemoglobin of less than $12.5 \mathrm{~g} / \mathrm{dL}$. Hb recovery in participants who did not take supplements was significantly faster in the highest-quartile ferritin subgroup $(51-192 \mathrm{ng} / \mathrm{mL})$ than in the lowest ferritin subgroup $(4-15 \mathrm{ng} / \mathrm{mL})^{[18]}$. This demonstrated that lower ferritin donors need more time to recover their $\mathrm{Hb}$ level.

There appears to be no reported evidence citing whether age has a relationship with iron status in plateletphesis donors. Here we found that age had no correlation with iron deficiency, but was clearly correlated with depleted iron stores. Multivariate analysis did not show there was association between age and reduced iron stores. A genome-wide association study reported that the ABO locus was significantly associated with ferritin levels ${ }^{[19]}$. B blood group donors in Bangladesh had the lowest serum ferritin level ${ }^{[20]}$. Moreover, Danish donors with non-O blood groups were found to have lower O blood groups. Accordingly, risk of ferritin level of less than $15 \mathrm{ng} / \mathrm{mL}$ was increased for individuals with non-O blood group compared with $\mathrm{O}$ blood group ${ }^{[21]}$. However, in an
Australian study there was no significant difference in the prevalence of iron deficiency in different blood group ${ }^{[6]}$, which was in accordance with the findings of our study.

In this study, repeated plateletpheresis donors of Chinese origin had lower serum ferritin levels and higher prevalence of reduced iron stores than first time donors, although their pre-donation $\mathrm{Hb}, \mathrm{Hct}, \mathrm{RBC}$ and platelet counts all met current Chinese standards. However, the number of donations and lower hemoglobin may be factors that influence iron stores, so more attention should be paid to monitor the iron stores of such groups of repeated donors, especially if their $\mathrm{Hb}$ is less than $130 \mathrm{~g} / \mathrm{L}$ and/or have donated more than 10 times. If appropriate, serum ferritin measurement and iron supplementation are strongly recommended.

\section{Acknowledgments}

This study was supported by grants of Jiangsu Province Fifth 333 Talent Program (2016-III-3345) and Jiangsu Commission of Health (LGY2016045 and S2017006).

\section{References}

[1] Simon TL, Garry PJ, Hooper EM. Iron stores in blood donors[J]. JAMA, 1981,22(20):2038-2043

[2] Spencer B. Blood donor iron status: are we bleeding them dry? [J]. Curr Opin Hematol, 2013; 20(6):533-539.

[3] Vuk T, Magnussen K, De Kort W, et al.International forum: an investigation of Iron status in blood donors[J]. Blood Transfusion, 2017,15(1):20-41

[4] Cable RG, Glynn SA, Kiss JE, et al.Iron deficiency in blood donors: analysis of enrollment data from the REDS- II Donor Iron Status Evaluation (RISE) study[J]. Transfusion, 2011,51(3):511-522

[5] Lee CK, Wong HK, Hong J, et al. A study of the predonation hemoglobin and Iron status among Hong Kong Chinese blood donors[J]. Transfusion, 2013,53(2):322-327

[6] Salvin HE, Pasricha SR, Marks DC. Iron deficiency in blood donors: a National cross-sectional study[J]. Transfusion, 2014,54(10):2434-2444

[7] Page E, Harrison J, Jaldow E, et al. Impairment of shorttermmemory associated with low Iron stores in a volunteer multidose plateletpheresis donor[J]. Transfus Med, 2008, 18(5): 312

[8] Page EA, Coppock JE, Harrison JF. Study of Iron stores in regular plateletpheresis donors[J]. Transfus Med,2010, 20(1):22-29

[9] Manascero-Gomez AR, Bravo-Espinosa M, Salano-Muriel $\mathrm{K}$, et al. Influence of blood donation time intervals on ferritin and haemoglobin concentration[J]. Transfus Apher Sci, 2015,53(2):213-219

[10] Li HH, Condon F, Kessler D, et al. Evidence of relative Iron deficiency in platelet-and plasma-pheresis donors 
correlates with donation frequency[J]. J Clin Apher, 2016,31(6):551-558

[11] Duggan F, O’sullivan K, Power JP, et al. Serum ferritin in plateletpheresis and whole blood donors[J]. Transfusion Aphere Sci, 2016,55(1):159-163

[12] Ma CH, Guo RH, Wu WJ, et al. Serum ferritin in donors with regular plateletpheresis[J]. J Experiment Hematol (in Chinese), 2011;19:508-10.

[13] Huang CY, Shi GY, Cai L, et al. Evaluation the effects on Iron stores among frequent plateaphesis donors[J]. $J$ Chinese Blood Transfusion (in Chinese), 2010,23(1):4243

[14] Zhou Q, Yu X, Cai Y, et al. Changes in pre-and postdonation platelet function in plateletpheresis donors[J]. Transfusion Clin Biologique, 2017,24(4):417-421

[15] The Chinese Center for Disease Control and Prevention. Survey on Nutrition and Chronic Diseases in China[R], Beijing: The Chinese Center for Disease Control and Prevention, 2015

[16] He JJ, Shen X, Fang AP, et al. Association between predominantly plant-based diets and iron status in Chinese adults: a cross-sectional analysis[J]. Bri J Nutrition, 2016,116(9):1621-1632

[17] World Health Organization. Worldwide prevalence of anaemia 1993-2005[R]. Geneva: World Health Organization, 2008

[18] Kiss JE, Brambilla D, Glynn S, et al. Oraliron supplementation after blood donation:a randomized clinical trial[J]. JAMA, 2015,313(6):575-583

[19] Benyamin B, Esko T, Ried JS, et al. Novel loci affecting iron homeostasis and their effects in individuals at risk for hemochromatosis[J]. Nat Commun, 2014,5:4926.

[20] Hoque MM, Adnan SD, Karim S, et al. Relationship between serum Iron profile and blood groups among the voluntary Blood donors of Bangladesh[J]. Mymensingh Med J, 2016,25(2):340-348

[21] Rigas AS, Berkfors AA, Pedersen OB, et al. Reduced ferritin levels in individuals with non-O blood group:results from the Danish Blood Donor Study[J]. Transfusion, 2017,57(12):2914-2919

(Received 17 June 2019, Revised 16 July 2019, Accepted 6 August 2019) 